but this implies both that the ants carry in material in excess of the ant colony's needs and that the route of movement of ${ }^{14} \mathrm{C}$ is directly from the food material to the plant. From the data available at present, it is still possible that the ants are acting entirely out of self-interest and are consuming all food entering the cavity so that ${ }^{14} \mathrm{C}$ entering the plant is derived only from faeces. If this latter explanation is correct, then the ant loses nothing from the association since there is no undue energy investment on its part. In either event, the plant very obviously gains from the association in both its organic and inorganic uptake. The presence of the ants must therefore represent an energy resource for the plant which supplements its photosynthetic intake. It could be regarded as a symbiotically adapted facultative saprophyte.

The coevolution of plants and animals has led to such very obvious structures as flowers and thorns and to the evolution of a variety of chemical compounds from tannins to cardiac glycosides. It should not come as any surprise, therefore, to find that in taking advantage of the grazer the apparently passive plant is less green than it's cabbage-looking.

\title{
New ways of applying pesticides
}

\section{from Graham Richards}

AT the biochemical level there is much in common between medical pharmaceutical research and the development of pesticides for agriculture. The great difference lies in overcoming the problem of application which is so much more difficult when dealing with plants. Researchers in this area have likened their problem to attempting to cure the common cold by dropping aspirins from an aircraft and hoping to catch a fair percentage of the population looking skywards with their mouths open. Small wonder then that the paper which caused the greatest interest at the 1979 British Crop Protection Conference held in Brighton* was the description by R.A. Coffee (ICl Plant Protection Division, Haslemere, Surrey) of an electrodynamic method suitable for the deposition of ultra-low volume droplets of insecticides, fungicides and herbicides.

In principle, the technique is akin to the famous Millikan oil drop experiment whereby the charge of the electron was first measured, and is similar in some respects to methods used in paint spraying. The sensational qualities are that Coffee's new design is free of any moving parts and can be run on torch batteries. Above all the droplets have curved trajectories so that when spraying the front of a plant the chemical is also delivered to the back.

The system which can be hand-held uses a gravity feed to supply liquid to a highvoltage nozzle. This voltage is achieved from the torch batteries using a solid-state converter. The emergent charged liquid drops are subjected to an intensely divergent electric field which is sufficient to carry the droplets to the target which is at earth potential. This field strength is about two orders of magnitudes greater than the gravitational pull, making for very much reduced drift and wind influence.

Graham Richards is a lecturer in the Physical Chemistry Laboratory, University of Oxford.

"British Crop Protection Conference - Pests and Diseases was held in Brighton, UK, on 19-22 November, 1979. Vol III of the Proceedings will be published in March 1980.
The almost magical quality of being able to deliver pesticides to the hidden surfaces of a plant when apparently spraying only one side arises from the curved flux lines of the electrically propelled droplets. As the
Poisson equation demands, the lines of force are orthogonal to the equipotential contours so that the spray diverges from the high voltage nozzle only to converge on the earthed target and thus to penetrate to surfaces which are not visible on a direct line of sight from the sprayer.

A nozzle flow rate of about $0.1 \mathrm{ml} \mathrm{s}^{-1}$ corresponds to a spray volume of as low as half a litre per hectare; the droplets being of about $100 \mu \mathrm{m}$ diameter (a power of 18 $\mathrm{mW}$ ). This ultra-low volume application has many attractions. Most obviously it should lead to a significant reduction of environmental problems associated with crop spraying. The simplicity of the device should also mean that it can be used by peasant farmers in the less sophisticated parts of the world where the introduction of chemical aids can produce as much as a 10 -fold increase in land cultivation.

Finally the device is an encouragement to chemists and researchers in crop protection since if the delivery of their compounds becomes more efficient then more expensive chemicals become economically viable and one constraint on their research is at least slackened.

\section{Inbreeding among zoo animals}

\section{from Robert M. May}

IMPROBABLY located off Wiltshire Boulevard in Los Angeles is a small park containing the Rancho la Brea tar pits. Here the bones of creatures - dire wolves, sabretooth tigers, mammoths, ground sloths - from the romantically envisioned 'Rancho la Brean fauna' may be seen, both in existential clutters of bones in the original tar pits, and in analytic exhibits. These large mammals flourished in North America until comparatively recently, when 35 of 49 genera became extinct in the short period from roughly 11,000 to around 8,000 years ago; many people believe the extinctions were caused by the arrival in North America of the comparatively advanced Clovis and Folsom hunters at that time (Martin Nature 212, 339; 1966).

The largest bird of those times was the now-extinct Teratornis incredibilis, whose wingspread of about 16 feet makes it the biggest soaring bird of prey yet to have lived. Its smaller congener, $T$. merriami, with a 12-foot wingspan and an estimated weight of $50 \mathrm{lbs}$, followed it into oblivion. The greatest bird of the Rancho la Brean fauna that survives is the California condor, with a wingspan of over 9 feet and a weight around $23 \mathrm{lbs}$; here I resolve the taxonomic pedantry of whether the Pleistocene Gymnogyps amplus and the present-day $G$. californianus are really two species, or the same species separated in time, by referring to both as the California condor. (Note that the three birds, which occurred together over part of their pristine ranges, form a nice Hutchinsonian sequence, with length ratios around 1.3 and weight ratios around 2; for an irreverent discussion of these ratios, see Nature 270, 660; 1977.)

The California condor's chances of continued existence are, however, slim. Its Pleistocene range, west of the Rocky Mountains from British Columbia to Baja California and east of the Rockies in a great southern strip extending to Florida, has narrowed to two counties in southwestern California, in the dry, mountainous parts of the southern Coast range and the Sierra Nevada. The total population has fallen from an estimated 60 in the 1940 s, to 42 in 1963 , to 30 today. Some of the loss is demonstrably due to wanton shooting by idiots exercising their 'right to bear arms'. The breeding rate (typically one egg per year) is not calculated to rebound from such vicissitudes. Even this potential recruitment is not being realised, possibly because of the many disturbances associated with increasing human encroachment in the habitat, and possibly because pesticides in the food supply are weakening the birds' egg shells.

There is currently much controversy about what to do (see NY Times, 23 Dec. 1979, A17). Various Federal and California agencies, along with the National Audubon Society, have signed an

Robert M. May is Class of 1877 Professor of Zoology at Princeton University. 